\title{
Influence of Total Intravenous Anesthesia, Entropy and Laparoscopy on Oxidative Stress
}

\author{
Rogean Rodrigues Nunes ${ }^{1}$, Fernando Squeff Nora ${ }^{2}$, Danielle Maia Holanda Dumaresq ${ }^{3}$, \\ Rute Maria Araújo Cavalcante ${ }^{4}$, Amanda Antunes Costa ${ }^{5}$, Lara Moreira Mendes Carneiro ${ }^{5}$, \\ Julio Cesar Garcia de Alencar ${ }^{5}$, Flávia Pereira Fernandes Cardoso ${ }^{5}$
}

Summary: Nunes RR, Nora FS, Dumaresq DMH, Cavalcante RMA, Costa AA, Carneiro LMM, Alencar JCG - Influence of Total Intravenous Anesthesia, Entropy, and Laparoscopy on Oxidative Stress.

Background and objectives: Recent studies have correlated postoperative mortality with anesthetic mortality, especially with the depth of anesthesia and systolic blood pressure (SBP). The aim of this study is to evaluate the effects of the depth of total intravenous anesthesia (TIVA) using remifentanil and propofol, performed with monitoring of response entropy (RE) on blood concentrations of oxidative stress markers (TBARS and glutathione) during laparoscopic operations.

Method: Twenty adult patients, ASA I, BMI 20-26 kg.m-2, aged 20 to 40 years, were randomly distributed into two groups: Group I underwent anesthetic-surgical procedure with RE maintained between 45 and 59, and Group II underwent anesthetic-surgical procedure with RE between 30 and 44. In both groups, the remifentanil and propofol infusion was controlled by the effector site (Es), adjusted to maintain RE desired values (Groups I and II) and always assessing the suppression rate (SR). Patients were evaluated in six periods: M1 (immediately before anesthesia), M2 (before tracheal intubation [TI]), M3 (5-minutes after TI), M4 (immediately before pneumoperitoneum [PPT]), M5 (1-minute after PPT), and M6 (1-hour after the operation). The following parameters were assessed at all times: SBP, DBP, HR, RE, SR, TBARS, and glutathione.

Results: We found increases in TBARS and glutathione in M5, both in Group I and Group II ( $<0.05)$, with higher values in Group II, and SR in three patients in Group II, immediately after PPT.

Conclusions: Increased markers in Group I (M5) suggests an increase in anaerobic metabolism (AM) in the splanchnic circulation while the highest values seen in Group II (GII > GI in M5, p < 0.05\%) suggest interference of another factor (deep anesthesia) responsible for the increase in AM, probably as a result of increased autonomic nervous system depression and minor splanchnic self-regulation.

Keywords: Entropy; Intravenous Anesthesia; Laparoscopy; Oxidative Stress.

C2012 Elsevier Editora Ltda. All rights reserved.

\section{INTRODUCTION}

Recent studies suggest that postoperative mortality may be influenced by anesthetic management during surgery, particularly control of anesthetic depth and systolic blood pressure. Major surgeries, severe trauma, sepsis, respiratory distress syndrome, ischemia and reperfusion (laparoscopic procedures) are important components of acute inflammation and

Received from Hospital São Carlos, Fortaleza, CE, Brazil.

1. MD; Clinical Director of Hospital São Lucas

2. Anesthesiologist; Member of the Câmara Técnica de Anestesiologia do CRM/RS

3. Responsible for CET of Instituto Dr. José Frota (IJF), Fortaleza; Scientific Director of SAEC

4. R3 Anesthesiologist, IJF, Fortaleza

5. Medical Undergraduate Student

Submitted on September 10, 2010.

Approved on November 23, 2011.

Correspondence to:

Dr. Rogean Rodrigues Nunes

Avenida Comendador Francisco Ângelo, 1185, casa

Dunas

60181500 - Fortaleza, CE, Brazil

E-mail: rogean@fortalnet.com.br represent a new challenge for anesthesiologists when managing drugs and anesthetic techniques ${ }^{1}$. Many animal and human studies have shown a decrease in endogenous antioxidants in oxidative stress conditions (oxidant and antioxidant imbalance favoring the former, i.e., a chemical-biological state in which production of reactive oxygen species exceeds the antioxidant capacity), particularly in ischemia-reperfusion injury and, more recently, systemic inflammatory response syndrome (SIRS). Excessive production of reactive oxygen species is one of the mechanisms founded in the pathogenesis of inflammatory reactions in response to trauma, surgery, sepsis, organ transplants, burns, and ischemia and reperfusion (I/R) 2,3 . In aerobic systems, the balance between oxide-reducing agents (such as ROS) and antioxidant defense system is essential ${ }^{3-5}$. These agents are endogenously generated as a direct result of $\mathrm{O}_{2}$ metabolism, and in non-physiological conditions such as cell exposure to xenobiotics that cause incomplete reduction of $\mathrm{O}_{2}$. For protection, the cell has a two-line defense system. One detoxifies the agent before it causes injury, consisting of reduced glutathione (GSH), superoxide dismutase (SOD), catalase, glutathione peroxidase (GSH-Px), and vitamin E (tocopherol $\alpha$ ); and the other acts to repair the damage occurred, consisting of ascorbic acid, glutathione-reductase (glutathione), and GSH-Px, among others. With the exception of 
vitamin E, a membrane structural antioxidant, the antioxidants are mostly located intracellularly. Other molecules, such as alpha and beta-carotene, ubiquinol, and cysteine, also remove free radicals ${ }^{4,6}$. This study aim was to evaluate the effects of pneumoperitoneum (ischemia-reperfusion injury) on oxidative stress and lipid peroxidation and the influence of adequate anesthesia with total intravenous anesthesia (TIVA), monitored by EEG on in vivo concentrations of oxidative stress markers and lipid peroxidation (glutathione and TBARS).

\section{METHOD}

A prospective, randomized study, conducted after approval by the Clinical Research Ethics Committee and signing of informed consent.

\section{Case report}

We evaluated 20 female patients who underwent videolaparoscopic operations for oophorectomy or myomectomy, physical status ASA I, aged between 20 and 50 years, and body mass index between 22 and 26 . Patients were randomly assigned into two groups of 10 individuals before induction of anesthesia: Group I (more superficial anesthesia), TIVA to maintain response entropy (RE) between 45 and 59. Group II (deeper anesthesia), TIVA to maintain RE between 30 and 44 .

\section{Equipment used}

1) Entropy Module; EEG signal is collected from the frontotemporal region and treated by Shannon's equation ${ }^{7}$ $\left(H=-p_{k} \log p_{k}\right)$, where $p_{k}$ is the probability of a discrete $k$ event, resulting in two types of analyzes: a) state entropy (SE), which is the evaluation of cerebral cortex electrical activity $(0.8-32 \mathrm{~Hz})$; and b) response entropy $(R E)$, which analyzes frequencies from 0.8 to $47 \mathrm{~Hz}$ (containing both cortical and subcortical EEG components). The frontal muscles activation may indicate inadequate subcortical component (bulb-pontine region). This way, there is the possibility of assessing anesthetic depth with a mixed-index; however, the time window of response entropy is lower than the state entropy, allowing a more rapid adjustment of anesthetic components ${ }^{8,9}$. In addition to these data, the equipment also evaluates the presence of burstsuppression (BS), which may be indicative of cerebral hypoperfusion in the absence of other factors, such as deep hypothermia, too deep anesthesia or both.

The assembly used was unilateral referencial, with the explorer electrode positioned at FT10 (frontotemporal region) and the reference electrode at Fpz (frontopolar) (Figure 1). This determines that the EEG tracing obtained is single channel (left or right, depending on the frontotemporal electrode position).

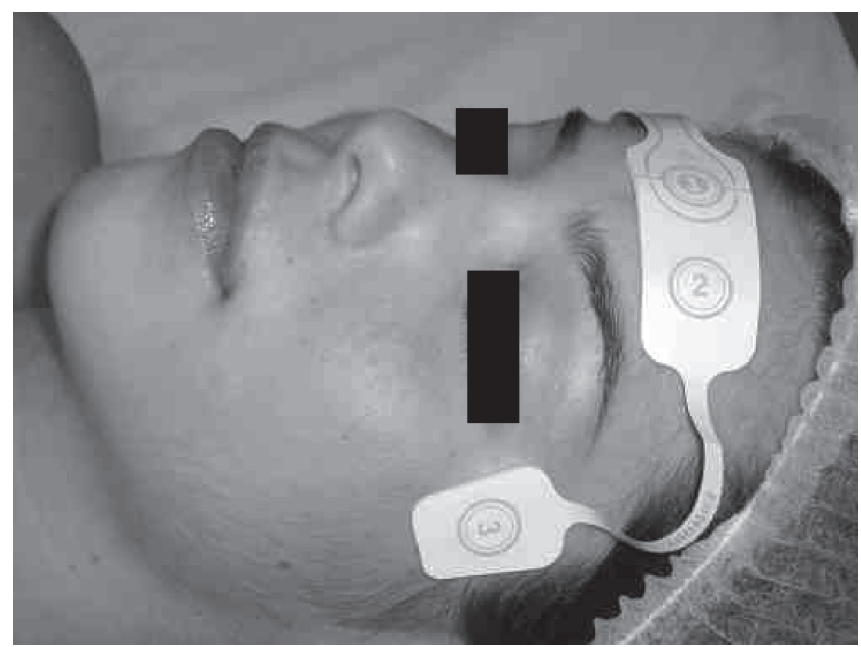

Figure 1 - Entropy Electrodes Assemblement.

2) Infusion pump with control target (plasma and effector site) for remifentanil and propofol using the following pharmacokinetic models: Minto for remifentanil and Marsh for propofol; 3) Two channels electrocardiogram - DII and V5; 4) Pulse oximetry; 5) Capnography and capnometry; 6) Automatic non-invasive blood pressure; 7) Air heater forced convection heat; 8) Specific material for plasma markers collection; 9) Thermometer with nasopharyngeal sensor.

\section{Preoperative evaluation}

All patients underwent clinical and laboratory evaluation preoperatively.

\section{Anesthesia technique}

None of the patients received premedication. All patients were subjected to the effects of the same surgical anesthetic and technique, maintaining a pneumoperitoneum pressure of $12 \mathrm{~mm} \mathrm{Hg}$ and flow of $3 \mathrm{~mL} \cdot \mathrm{min}^{-1}$. After venipuncture in the right upper limb, all patients received an infusion of saline solution $\mathrm{NaCl}$ 0.9\% (2 mL. $\mathrm{kg}^{-1}$ for fast replacement and $6 \mathrm{~mL} . \mathrm{kg}^{-1}$ for replacement of losses during surgery). Anesthesia was induced with concurrent intravenous propofol infusions performed with the aid of infusion pumps controlled by the effector site (Es), with initial target of $4 \mu \mathrm{g} \cdot \mathrm{mL}^{-1}$ and remifentanil, Es, with initial target of $4 \mathrm{ng} \cdot \mathrm{mL}^{-1}$ until the response entropy (RE) value reached 40 . If $R E$ did not reach 40 , the Es concentration of remifentanil would be increased by $0.5 \mathrm{ng} \cdot \mathrm{mL}^{-1}$ until achieving a RE of 40 . At this point, the Es concentration of remifentanil would be fixed and orotracheal intubation per- 
formed (OTI). In Group I, propofol and remifentanil infusions were adjusted to maintain a RE of 45-59. In Group II, infusions of propofol and remifentanil were adjusted to maintain a RE of $30-44$. In both groups, pre-oxygenation with $100 \%$ oxygen was performed under mask 5 minutes before induction of anesthesia until immediately before tracheal intubation. Neuromuscular block was not used because it may interfere with the processed EEG values ${ }^{10}$. Management of anesthesia maintenance was performed according to the guidelines specified in Chart 1.

However, RE values within specified limits (Groups I and II) were adjusted as follows: determining the degree of hypnosis by RE and assessing the analgesia by systolic blood pressure (SBP), which should not exceed $20 \%$ of baseline value (M1) for the upper limit, nor fall below $80 \mathrm{mmHg}$ for the lower limit. Thus, after OTI, propofol was titrated in concentrations sufficient to maintain the specified values of RE for Groups I and II, and remifentanil was adjusted according to the concentration required to maintain PAS within the variations specified in this protocol. Changes in propofol concentrations were performed by $0.5 \mu \mathrm{g} \cdot \mathrm{mL}^{-1}$, with subsequent variations performed only after achieving the concentration at the effector site, provided by the infusion pump. The same procedure was applied to remifentanil, with variations by $0.1 \mathrm{ng} \cdot \mathrm{mL}^{-1}$. Heart rate with variations greater than $\pm 25 \%$ from baseline (M1) were considered clinically significant. After tracheal intubation, respiratory rate was adjusted to maintain $\mathrm{P}_{\mathrm{ET}} \mathrm{CO}_{2}$ between 35 and 40 $\mathrm{mmHg}, \mathrm{FiO}_{2} 35 \%$, with a tidal volume of $8 \mathrm{~mL} . \mathrm{kg}^{-1}$. Ventilation was performed in a circle system with $\mathrm{CO}_{2}$ reabsorber.

Chart 1 - Strategies to Maintain Anesthesia with EEG-Based Monitoring.

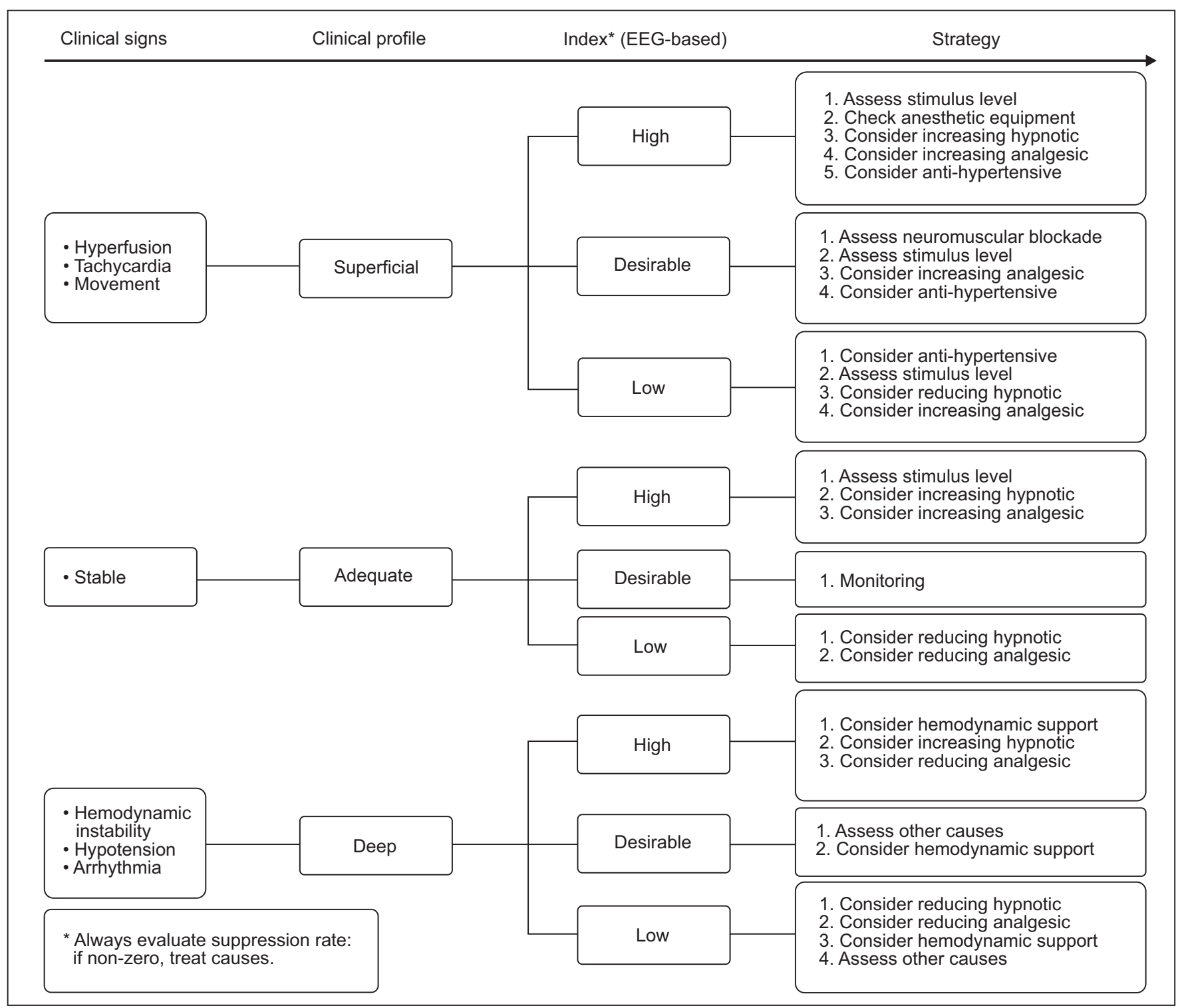


For clinical study purposes and statistical analysis, six times were assessed: M1, admission to the surgical center; M2, immediately before tracheal intubation; M3, 5-minute after tracheal intubation; M4, immediately before pneumoperitoneum installation; M5, 1-minute after the end of pneumoperitoneum; and M6, 1-hour after the operation. At each time, the following variables were recorded: systolic and diastolic blood pressure, heart rate, hemoglobin peripheral saturation, expired carbon dioxide concentration, and nasopharyngeal temperature. Plasma markers of oxidative stress (TBARS and glutathione) were determined in venous blood samples at the following times: M1, M2, M3, M4, M5, and M6. The awakening time was considered as the time elapsed from cessation of anesthetic agents to RE greater than or equal to 90 . The duration of the operation was considered as the time elapsed from skin incision to the end of the dressing and the duration of anesthesia from the start of remifentanil infusion until extubation.

In all patients, the nasopharyngeal temperature was maintained between $35^{\circ}-36^{\circ} \mathrm{C}$ with the aid of forced-air convection thermal blanket. The maximum value for Trendelenburg position was considered at $15^{\circ}$. EEG data were measured using a specific device (processed EEG), with sensor recommended by the manufacturer at the following points: FT10 (signal capture of frontotemporal region), FP2 (artifact elimination), and Fpz (reference), coupled to an analog-digital converter. Data were computed after impedance test performed by the device and subsequent reading. At the end of the procedure, the same respiratory rate was maintained and administrations of remifentanil and propofol interrupted. We also evaluated the time of hospital discharge, interval between tracheal extubation, and satisfactory Romberg, with the latter performed by asking the patient to remain standing up, still, with feet close together, and eyes closed. The test is considered satisfactory when the patient can maintain this posture for one minute. This test was performed every 15 minutes, starting 10 minutes after the patient could maintain the sitting position without assistance.

\section{Venous blood collection for plasma markers measurement}

Samples were collected by venous catheter (cephalic vein), using $10 \mathrm{~mL}$ disposable syringe by the method of two syringes.

\section{Determination of the concentration of thiobarbituric acid reactive substances (TBARS)}

The evaluation of lipid peroxidation (indicating cell damage) was performed by reaction with thiobarbituric acid.

\section{Determination of glutathione concentration}

The determination of glutathione concentration is based on the reaction of 2-nitrobenzoic acid with the free thiol, yielding a mixed disulfide plus 2-nitro-5-thiobenzoic acid. Measurement of the product reaction formation is performed in a Beckman spectrophotometer by reading the absorbance at $412 \mathrm{~nm}$.

\section{Evaluation criteria}

The data obtained from hemodynamic, autonomic, pharmacodynamic, metabolic or oxidative parameters were compared both between times in the same group and between groups at equivalent times.

\section{Statistical analysis}

We used the analysis of variance according to the repeated measures model with two factors of classification (group and time) and Tukey's test for comparison of measurements of time within the group and group within time, considering as statistically significant $p<0.05$.

\section{RESULTS}

Both groups were homogeneous regarding age, BMI, physical condition, height (Table I) and duration of pneumoperitoneum (Table II). Duration of anesthesia in Group I was $118.00 \pm 6.10$ minutes and in Group II $114.00 \pm 5.22$ minutes ( $p>0.05$ ). Duration of operation in Group I was $82.80 \pm 4.81$ minutes and $75.40 \pm 7.20$ minutes in Group II ( $p<0.05)$. Awakening time in Group I was $7.70 \pm 1.24$ minutes and $10.20 \pm 0.90$ minutes in Group II ( $<$ 0.05) (Table III). All patients could be extubated immediately after awakening. The time of hospital discharge was $362.40 \pm 14.80$ minutes in Group I and $430.50 \pm 17.81$ minutes in Group II ( $p<0.05)$, values considered not clinically relevant (Table III). SBP, DBP, and HR values are shown in Table IV and did not exceed the limits established in the protocol.

Regarding $\mathrm{ER}$, the values at M1 and M6 are significantly different from M2, M3, M4, and M5, both in Group I and Group II $(p<0.05)$ (Table V). As for intergroup assessment, there is significant difference between measurements regarding the interaction effect of time-groups for significance levels less than $5 \%$ at the following times: M2, M3, M4, and M5 (Figure 2).

Regarding suppression rate, which in this study represents deleterious cellular changes in CNS, there were three cases in Group II immediately after pneumoperitoneum.

Analysis of oxidative stress markers showed, with respect to glutathione, significant differences between M4 and M5, comparing the GI and GIl alone. Analysis of groups within each time showed significant different at M5 and M6 $(p<0.05)$ (Table VI, Figure 3).

Regarding TBARS variable, which is related to lipid peroxidation, there was a significant increase in both Group I and Group II between M4 and M5, with the highest values recorded in Group II, and analysis of both groups within each time showed significant differences at M5 and M6, with higher values seen in Group II (Table VII, Figure 4).

Table I - Variables: Age, Weight and Height (Mean \pm SD)

\begin{tabular}{llll}
\hline Groups & Age (years) & Weight $(\mathrm{kg})$ & Height $(\mathrm{cm})$ \\
\hline I & $30.50 \pm 2.95$ & $64.7 \pm 3.15$ & $163.20 \pm 3.45$ \\
II & $28.00 \pm 3.65$ & $61.3 \pm 4.05$ & $160.70 \pm 3.02$ \\
\hline
\end{tabular}


Table II - Duration of Pneumoperitoneum by Group (Mean \pm SD)

\begin{tabular}{llllll}
\hline Pneumoperitoneum & Groups & N & Minimum & Maximum & Mean \pm SD \\
\hline Duration (min) & I & 10 & 60 & 70 & $61.90 \pm 2.50$ \\
& II & 10 & 56 & 64 & $62.40 \pm 3.32$ \\
\hline
\end{tabular}

Table III - Duration of Anesthesia, Duration of Operation, Awakening Time, and Time of Hospital Discharge by Group (Mean \pm SD)

\begin{tabular}{lllll}
\hline Groups & $\begin{array}{l}\text { Duration of Anesthesia } \\
(\mathrm{min})\end{array}$ & $\begin{array}{l}\text { Duration of Operation } \\
(\mathrm{min})\end{array}$ & $\begin{array}{l}\text { Awakening Time } \\
(\mathrm{min})\end{array}$ & $\begin{array}{l}\text { Time of Hospital } \\
\text { Discharge }(\mathrm{min})\end{array}$ \\
\hline $\mathrm{I}$ & $118.00 \pm 6.10$ & $82.80 \pm 4.81$ & $7.70 \pm 1.24$ & $362.40 \pm 14.80$ \\
$\mathrm{II}$ & $114.00 \pm 5.22$ & $75.40 \pm 7.20^{*}$ & $10.20 \pm 0.90^{*}$ & $430.50 \pm 17.81^{*}$ \\
\hline
\end{tabular}

${ }^{*} p<0.05$.

Table IV - Heart Rate (HR), Systolic Blood Pressure (SBP), and Diastolic Blood Pressure (DBP) by Group (Mean \pm SD)

\begin{tabular}{lllll}
\hline Time & Groups & HR & SBP & DBP \\
\hline M1 & & Mean \pm SD (beats. min $\left.{ }^{-1}\right)$ & Mean \pm SD $(\mathrm{mm} \mathrm{Hg})$ & Mean \pm SD $(\mathrm{mm} \mathrm{Hg})$ \\
& I & $77.00 \pm 7.13$ & $110.70 \pm 9.24$ & $75.70 \pm 4.32$ \\
M2 & II & $73.70 \pm 7.07$ & $111.90 \pm 5.07$ & $74.20 \pm 3.79$ \\
& I & $66.70 \pm 4.47$ & $94.30 \pm 5.21$ & $61.00 \pm 4.27$ \\
M3 & II & $63.00 \pm 3.97$ & $95.80 \pm 8.48$ & $67.00 \pm 3.46$ \\
& I & $69.10 \pm 2.77$ & $96.00 \pm 9.35$ & $69.00 \pm 2.98$ \\
M4 & II & $65.40 \pm 2.46$ & $97.60 \pm 8.97$ & $65.80 \pm 4.21$ \\
& I & $67.30 \pm 4.21$ & $95.20 \pm 7.76$ & $61.00 \pm 3.09$ \\
M5 & II & $62.30 \pm 3.47$ & $100.30 \pm 8.64$ & $62.60 \pm 3.81$ \\
& I & $71.10 \pm 5.51$ & $104.00 \pm 9.64$ & $71.60 \pm 3.84$ \\
M6 & II & $63.40 \pm 3.92$ & $106.20 \pm 10.08$ & $70.70 \pm 2.98$ \\
& I & $79.90 \pm 3.84$ & $114.90 \pm 7.40$ & $79.60 \pm 3.95$ \\
\hline
\end{tabular}

Table V - Electroencephalogram: RE (Mean \pm SD)

\begin{tabular}{llll}
\hline Groups & Time & N & Mean \pm SD \\
\hline \multirow{4}{*}{ I } & M1 & 10 & $96.60 \pm 3.80^{*}$ \\
& M2 & 10 & $52.20 \pm 2.10$ \\
& M3 & 10 & $53.40 \pm 1.90$ \\
& M4 & 10 & $55.70 \pm 2.30$ \\
& M5 & 10 & $52.40 \pm 2.60$ \\
II & M6 & 10 & $94.70 \pm 3.50^{*}$ \\
\hline \multirow{4}{*}{ M1 } & 10 & $98.20 \pm 3.40^{*}$ \\
& M2 & 10 & $36.20 \pm 3.60$ \\
& M3 & 10 & $38.40 \pm 3.40$ \\
& M4 & 10 & $36.10 \pm 3.90$ \\
& M5 & 10 & $39.30 \pm 2.30$ \\
& M6 & 10 & $96.90 \pm 2.70^{*}$ \\
\hline
\end{tabular}

${ }^{*} \mathrm{p}<0.05$. Intragroup assessment.

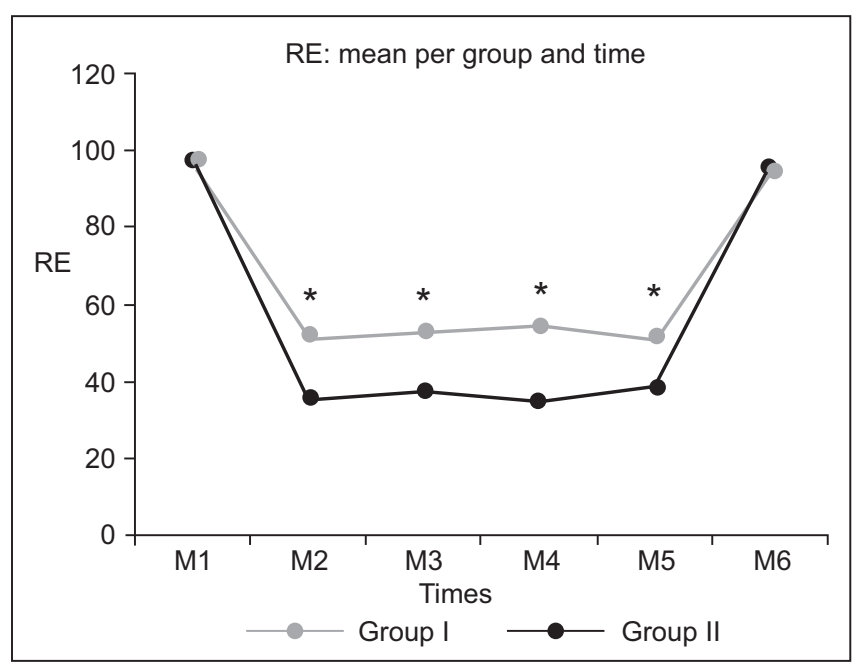

Figure 2 - RE and its Evaluation between Times.

${ }^{*} \mathrm{p}<0.05$ for M2-M5, between GI and GII. RE: response entropy. 


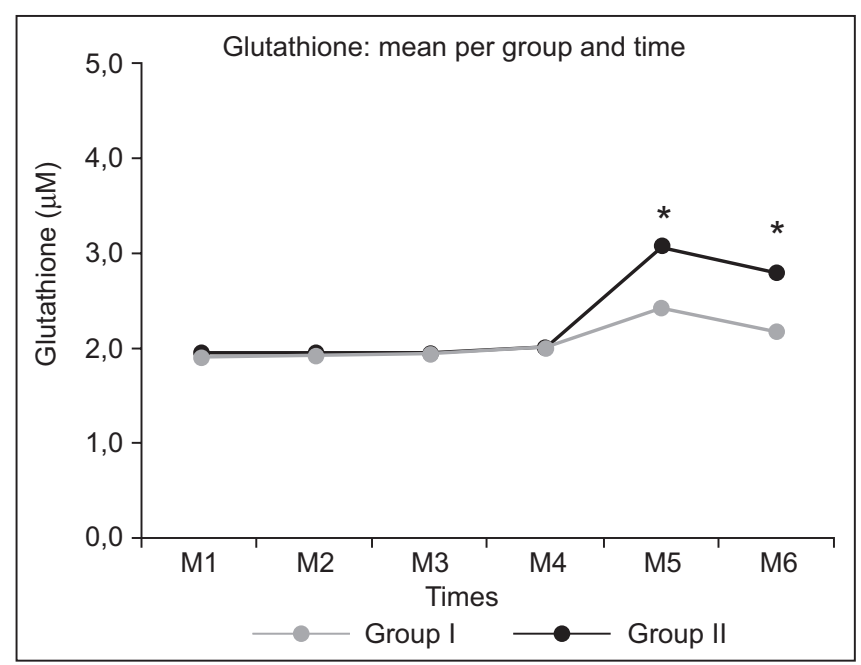

Figure 3 - Glutathione: Intergroup Analysis. ${ }^{*} \mathrm{p}<0.05$ for M5 and M6, between GI and GII.

Table VI - Glutathione Variable (Mean \pm SD)

\begin{tabular}{llll}
\hline Groups & Time & N & Mean \pm SD \\
\hline \multirow{4}{*}{ I } & M1 & 10 & $1.90 \pm 0.15$ \\
& M2 & 10 & $1.93 \pm 0.14$ \\
& M3 & 10 & $1.94 \pm 0.11$ \\
& M4 & 10 & $2.02 \pm 0.08$ \\
& M5 & 10 & $2.42 \pm 0.14^{*}$ \\
II & M6 & 10 & $2.18 \pm 0.05$ \\
\hline \multirow{4}{*}{ M1 } & 10 & $1.94 \pm 0.14$ \\
& M2 & 10 & $1.96 \pm 0.14$ \\
& M3 & 10 & $1.94 \pm 0.10$ \\
& M4 & 10 & $2.00 \pm 0.08$ \\
& M5 & 10 & $3.07 \pm 0.19^{\star}$ \\
\hline
\end{tabular}

${ }^{*} p<0.05$. Intragroup assessment.

Tabela VII - TBARS Variable (Mean \pm SD)

\begin{tabular}{llll}
\hline Groups & Time & N & Mean \pm SD \\
\hline \multirow{4}{*}{ I } & M1 & 10 & $0.02 \pm 0.01$ \\
& M2 & 10 & $0.02 \pm 0.01$ \\
& M3 & 10 & $0.02 \pm 0.01$ \\
& M4 & 10 & $0.03 \pm 0.01$ \\
& M5 & 10 & $1.66 \pm 0.46^{*}$ \\
II & M6 & 10 & $0.72 \pm 0.10$ \\
\hline \multirow{4}{*}{ M1 } & 10 & $0.02 \pm 0.01$ \\
& M2 & 10 & $0.02 \pm 0.01$ \\
& M3 & 10 & $0.02 \pm 0.01$ \\
& M4 & 10 & $0.02 \pm 0.01$ \\
& M5 & 10 & $5.10 \pm 0.68^{*}$ \\
\hline
\end{tabular}

${ }^{*} p<0.05$. Intragroup assessment.

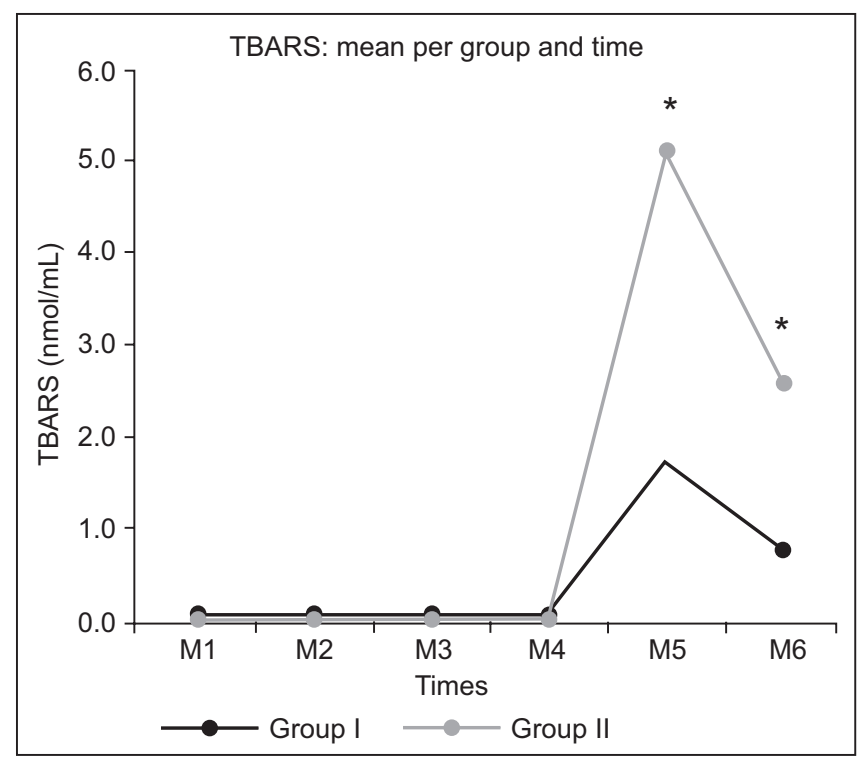

Figure 4 - TBARS: Intergroup Analysis.

${ }^{*} p<0.05$ for M5 and M6, between GI and GII.

\section{DISCUSSION}

The metabolic response to trauma is an increasingly important issue when general anesthesia is studied as a predictor factor of postoperative outcome. The predictors of intraoperative morbidity and mortality are divided into three categories: predictors related to the associated comorbidities, predictors attributable to the operation itself, and predictors associated with the anesthetic ${ }^{11}$. Currently, the risk of anesthesia during the immediate perioperative period seems to be rather small ${ }^{12}$. However, little is known about the effects of anesthetic on long-term results. Although no lasting benefit has been linked to specific anesthetic so far, studies suggest that local anesthesia may improve survival in certain patient groups ${ }^{13}$. Monitoring anesthetic depth is now possible thanks to the use of EEG digital signal processing techniques ${ }^{14}$. Although no technology, including pulse oximetry, has proven to reduce mortality, it has been suggested that anesthetic depth monitoring allows the use of exact dosages of anesthetics and thus to reduce the cardiovascular effects arising from overdoses ${ }^{15}$. A study by Monk et al. ${ }^{16}$ suggests that intraoperative anesthetic management, particularly depth and blood pressure control, may influence the mortality assessed in up to one year. The independent association of cumulative time of deep anesthesia with mortality in one year was a new finding in this study. Lindholm et al. ${ }^{17}$ evaluated data from bispectral index to assess the effects of monitoring on incidence of intraoperative awakening and showed that a cumulative BIS time of less than 45 was associated with an increased risk of death in evaluations up to two years after operation. Another recent study, analyzing long-term mortality, showed that the absence of a BIS less than 40 (deep an- 
esthesia) was associated with improved survival and reduced morbidity ${ }^{18}$. A study of comatose patients with ischemic encephalopathy who underwent emergency operation showed that data collected from BIS were better predictors than clinical judgment in identifying patients with a good chance of recovery ${ }^{19}$. Monitoring the depth of anesthesia using EEG produces data clinically useful, as routine practice results in large variation in anesthetic dose and patient's response 20 . Elderly patients or patients with several comorbidities require lower anesthetic doses than younger and healthier patients, which can be detected by EEG monitoring ${ }^{21}$. Previous studies probably failed to detect the effects of general anesthesia on long-term outcome because they focused on the type of anesthesia administered rather on quantity or effect of anesthetics on brain. Even when inhaled or total intravenous anesthesia is compared, it is necessary to maintain doses and concentrations of both agents equivalent to have the same anesthetic depth with both techniques. EEG monitoring is a non-invasive method that uses a specific algorithm that has a direct correlation with the adequacy or depth of anesthesia. Although universally used, the clinical signs to evaluate this adequacy are not reliable ${ }^{22}$. Clinical signs, such as blood pressure and heart rate, have widely dispersed probability indices to diagnose the possible superficiality of general anesthesia. Clinical signs are sensitive but less specific ( $\mathrm{Pk}$ ranging from 0.6 to $0.9)$, which can result in intraoperative awakening even in the absence of tachycardia and hypertension. Therefore, several equipments have emerged aiming at improving the management of intraoperative anesthetic drugs, some of them directly measuring cerebral cortical activity (hypnosis), subcortical activity, or both ${ }^{23}$. Taken into account that anesthetics and anesthetic techniques themselves are able to change significantly cytokine profiles ${ }^{16,24}$, the findings of an association between the depth and duration of anesthesia and mortality in one year raises the plausible hypothesis of a process mediated by cytokines. It is possible that prolonged deep anesthesia change the inflammatory response in high-risk patients, predisposing them to adverse outcomes. Glantzounis et al. ${ }^{25}$ found that free radicals are generated at the end of laparoscopic procedures possibly as a result of the ischemia-reperfusion phenomenon induced by inflation and deflation of pneumoperitoneum. However, patients in this study had a normal postoperative period, despite increased liver enzymes and lipid peroxidation. Other studies found a lower inflammatory response in videolaparoscopic operations compared to conventional colorectal operations ${ }^{26,27}$. Although a minor surgical trauma, hemodynamic changes determined by pneumoperitoneum involve both cardiac output and splanchnic perfusion, mainly intra-abdominal pressure over $15 \mathrm{~mm} \mathrm{Hg}{ }^{28,29}$. Videolaparoscopy procedures then became models of ischemia-reperfusion, where pneumoperitoneum installed during laparoscopy produces a condition similar to abdominal compartment syndrome ${ }^{30}$. In healthy patients, increased intra-abdominal pressure of 10 to $15 \mathrm{~mm} \mathrm{Hg}$ decreases the stomach blood flow by $54 \%$, jejunum by $32 \%$, colon by $44 \%$, liver by $39 \%$, parietal peritoneum by $60 \%$, and duodenum by $11 \%$. Splanchnic blood flow typically represents $29 \%$ of the cardiac output and remains reduced throughout the inflation time ${ }^{31}$. Perfusion of splanchnic system is performed through three major arteries (celiac artery and superior and inferior mesenteric arteries) and have a wide distribution of adrenergic receptors.

Experimentally, changes in visceral blood flow occur rapidly, even with moderate increases in intra-abdominal pressure ${ }^{32}$. Gastric mucosal hypoperfusion may persist during postoperative period because the recovery of splanchnic circulation triggered by the effects of pneumoperitoneum occurs more slowly than the systemic circulation ${ }^{33}$. Decreased intestinal perfusion is proportional to the values of intra-abdominal pressure. Reduction of splanchnic circulation perfusion is measured by mechanical compression of mesenteric vessels and vasoconstriction secondary to vasopressin secretion ${ }^{34}$. Increased intra-abdominal pressure and decreased blood flow may damage endothelial and Kupffer cells, while the head-up tilt position is related to decrease in total hepatic blood flow ${ }^{35}$. To avoid significant decreases in liver and splanchnic blood flow, intra-abdominal pressure should be maintained between 8 and $10 \mathrm{mmHg}$ and even smaller values than these ${ }^{31}$. Studies relating the depth of anesthesia based on EEG-ER and oxidative stress markers were not found in literature. However, Shimogai et al. ${ }^{36}$ described a significant reduction in BIS value when there was deflation of a pneumatic tourniquet on the lower limb of patients undergoing orthopedic surgery, speculating that the transient reduction of BIS may have been caused by direct toxicity of substances, such as hypoxanthine, produced during ischemia. In the present study, we found in Group II episodes of suppression in three patients, which may reflect direct cellular damage from substances released after pneumoperitoneum (PPN) deflation, in glial cells, and oligodendrocytes ${ }^{37}$. These neural cells require antioxidant defenses to cope with the continuous supply of reactive oxygen species (ROS) produced in the brain during aerobic metabolism. Oxidative stress is greatly increased during anaerobic respiration that occurs during ischemia and reperfusion. In culture, oligodendrocytes seem particularly sensitive to oxidative stress ${ }^{37}$. Some of the reasons proposed for the high vulnerability of oligodendrocytes, compared to other cells, include high lipid and iron content and reduction of antioxidant enzymes or limited substrates ${ }^{38}$. Thorburne et al. ${ }^{39}$ found that oligodendrocytes have low stocks of glutathione, which may have reflected the presence of suppression rate in Group II of our study, with no hemodynamic changes outside the clinically accepted standard. For this study, only the depth of anesthesia remained altered, which resulted in increases in blood markers of oxidative stress (TBARS and glutathione). These increases were statistically more significant in Group II (M5), influenced by the adequacy of anesthesia in this model of ischemia-reperfusion. Studies show that the autonomic nervous system activity is dose-dependent depressed by inhaled anesthetics 40,41 . Therefore, because autonomic nervous system is significantly modulated by the baroreceptor system (reflex mechanisms), the effects of inhaled anesthetics on efferent system also depend on the baroreflex arch integrity. Halothane, enflurane, and isoflurane ${ }^{42,43}$ depress the baroreflex control of heart rate in a dose-dependent manner, with isoflurane supposedly hav- 
ing the least effect. Similar responses in reflex control of heart rate have been shown with sevoflurane and isoflurane $42,44,45$. It has been observed dose-dependent depression of the reflex control of sympathetic outflow relatively equivalent for sevoflurane, isoflurane, and desflurane. Anesthesia with more superficial levels, i.e., 0.5 MAC has little effect on baroreceptor reflex function and this may be very important in patients with compromised clinical state. Opioids and benzodiazepines have only minimal effects on baroreceptor reflex function, which combined with low concentrations of inhaled agents may preserve these reflexes ${ }^{46,47}$. In the present study, with the use of TIVA (propofol and remifentanil) in both groups, there was significant increase of oxidative stress markers in Group II after pneumoperitoneum, showing that deeper anesthesia contributed to a greater oxidative stress or to a lesser control of it. Inhibition of the baroreceptor reflex activity occurs as a result of central nervous system depression, associated with changes in the afferent impulses, weakening of the efferent autonomic nervous system activity, reductions in ganglionic transmission, and responses of target organs. In this case, we observed as a complicating factor both the installation of pneumoperitoneum, with increased oxidative markers in Group I, and deep anesthesia, as in Group II showed significant increases during M5 compared to Group I at same time, showing that in this model of ischemia-reperfusion, deep anesthesia further contributed to exacerbate oxidative stress. According to Olshan et al. ${ }^{48}$ and Gribbin et al. ${ }^{49}$, the action of volatile anesthetics on baroreceptor reflexes, which exert major modulating effect on ANS, may promote significant changes in elderly patients with autonomic dysfunction or in those with essential hypertension, diabetes mellitus, or heart failure. Moreover, there is increased secretion of antidiuretic hormone $(A D H)$ stimulated by the pneumoperitoneum, which exerts a vasoconstrictor effect in the superior mesenteric artery, further compromising splanchnic perfusion ${ }^{34}$. These findings show that the pneumoperitoneum, with the pressures used, generated an increase in lipid peroxidation, as well as in the application of glutathione (with initial increase of this natural antioxidant), showing higher oxidative stress in response to splanchnic ischemia when RE was maintained between 45 and 59. In Group II, it was also observed (RE between 30 and 44 with deeper anesthesia) that the oxidative stress markers increased significantly in M5, more in GIl than GI ( $p$ 0.05), showing that deeper TIVA with remifentanil and propofol is a significant deleterious factor, in addition to pneumoperitoneum, and has contributed significantly to increase the oxidative stress.

In conclusion: 1) $\mathrm{CO}_{2}$ pneumoperitoneum, within the pressures used (12 $\mathrm{mm} \mathrm{Hg}$ ), resulted in significantly higher oxidative responses, indicating significant cell damage. 2) According to this study protocol, TIVA with remifentanil and propofol to maintain RE at lower values (deeper anesthesia) was associated with more intense oxidative responses in videolaparoscopic procedures, representing a deleterious factor in this model of ischemia-reperfusion.

This study allows us to suggest the use of lower intra-abdominal pressure during pneumoperitoneum, as well as better control of the anesthetic adequacy based on EEG. Future studies assessing long-term outcomes could determine these changes influence on morbidity and mortality, particularly in patients with comorbidities, in addition to better design of adjuvant methods able of reduce lipid peroxidation, such as vitamin $C$, vitamin E, glutamine, and other antioxidants. 


\section{REFERENCES}

01. Sherwood ER, Toliver-kinsky $T$ - Mechanisms of the inflammatory response. Best Pract Res Clin Anaesthesiol, 2004;18:305-405.

02. Fink MP - O papel das citocinas como mediadores da resposta inflamatória. Em: Townsend JR CM, Beauchamp RD, Evers BM, Mattox $\mathrm{KL}$ - Sabiston: Tratado de Cirurgia, $2^{\mathrm{a}} \mathrm{Ed}$, Elsevier: São Paulo, 2005, pp 45-66.

03. Weigand MA, Horner C, Bardenheuer HJ, Bouchon A - The systemic inflammatory response syndrome. Best Pract Res Clin Anaesthesiol, 2004;18:455-475.

04. Wilson JX, Gelb AW - Free radicals, antioxidants, and neurologic injury: possible relationship to cerebral protetion by anesthetics. J Neurosurg Anesthesiol, 2002;14:66-79.

05. Ferreira ALA, Matsubara LS - Radicais livres: conceitos, doenças relacionadas, sistema de defesa e estresse oxidativo. Rev Ass Med $\mathrm{Br}$, 1997;43:61-68.

06. Aldemir O, Celebi C, Cevik K, Duzung E - The effects of propofol on free radical prodution after tournequet induced ischaemia-reperfusion injury during knee arthroplasty. Acta Anaesthesiol Scand, 2001;45:1221-1225.

07. Shannon CE - A mathematical theory of communication. Bell Syst Tech J, 1948;27:379-423.

08. Viertïo-oja H, Maja V, Särkela M et al. - Description of the entropy ${ }^{\top M}$ algorithm as applied in the datex-ohmeda $\mathrm{s} / 5^{\mathrm{TM}}$ entropy module. Acta Anaesthesiol Scand, 2004;48:154-161.

09. Bein B - Entropy. Best Pract Res Clin Anaesthesiol, 2006;20: 101109.

10. Nunes RR, Cavalcante SL et al. - Influência do bloqueio neuromuscular despolarizante nas entropias. São Paulo Med J, 2007;125-126.

11. Fleisher LA, Anderson GF - Perioperative risk: How can we study the influence of provider characteristics?. Anesthesiology, 2002;96:10391041.

12. Arbous MS, Grobbee DE, van Kleef JW - Mortality associated with anaesthesia: A qualitative analysis to identify risk factors. Anaesthesia, 2001;56:1141-1153.

13. Rasmussen LS, Johnson T, Kuipers HM - Does anaesthesia cause postoperative cognitive dysfunction? A randomized study of regional versus general anaesthesia. Acta Anaesthesiol Scand, 2003;47:260266.

14. Glass PS, Bloom M, Kearse $L$ - Bispectral analysis measures sedation and memory effects of propofol, midazolam, isoflurane, and alfentanil in healthy volunteers. Anesthesiology, 1997;86:836-847.

15. Buhre W, Rossaint R - Perioperative management and monitoring in anesthesia. Lancet, 1997;362:1839-1846.

16. Monk TG, Saini V, Weldon BC, Sigl JC - Anesthetic management and one-year mortality after noncardiac surgery. Anesth Analg, 2005; 100:4-10.

17. Lindholm ML, Träff S, Granath F et al. - Mortality within 2 years after surgery in relation to low intraoperative bispectral index values and preexisting malignant disease. Anesth Analg, 2009;108:508-512.

18. Leslie K, Myles PS, Forbes A et al. - The effect of bispectral index monitoring on long-term survival in the B-ware trial. Anesth Analg, 2010;110:816-822.

19. Myles PS, Daly D, Silver A, Chan MTV - Prediction of neurological outcome using bispectral monitoring in patients with severe ischemic- hypoxic brain injury during emergency surgery. Anesthesiology, 2009;110:1106-1115.

20. Guignard B, Cost C, Menigaux C, Chauvin M - Reduced isoflurane consumption with bispectral index monitoring. Acta Anaesthesiol Scand, 2001;45:308-314

21. Katoh $T$, Sato $S$ - Influence of age on hypnotic requeriment, bispectral index, and $95 \%$ spectral edge frequency associated with sedation induced by isoflurane. Anesthesiology, 2000;92:55-61.

22. Nunes RR - Componentes da atividade anestésica: uma nova visão. Rev Bras Anestesiol, 2003;53:145-149.

23. Nunes RR, Almeida MP, Sleigh JW- Entropia espectral: um novo método para adequação anestésica. Rev Bras Anestesiol, 2004;54:404422.

24. Kudoh A, Katagai H, Takazawa $T$, Matsuki A - Plasma proinflammatory cytokine response to surgical stress in elderly patients. Cytokine, 2001;15:270-273

25. Glantzounis GK, Tselepis AD, Tambaki AP et al. - Laparoscopic surgery-induced changes in oxidative stress markers in human plasma. Surg Endosc, 2001;15:1315-1319.

26. Leung KL, lai PBS, Ho RLK et al. - Systemic cytokine response after laparoscopic-assisted resection of rectosigmoid carcinoma. Ann Surg, 2000;231:506-511.

27. Schwenk W, Jacobi C, Mansmann U, Böhn B, Müller JM - Inflammatory response after laparoscopic and conventional colorectal resections - results of a prospective randomized trial. Langenbeck's Archives Surgery, 2000;385:2-9.

28. Gerges FJ, Kanazi GE, Jabbour-khoury SI - Anesthesia for laparoscopy: a review. J Clin Anesth, 2006;18:67-78.

29. Gutt CN, Oniu T, Mehrabi A et al. - Circulatory and respiratory complications of carbon dioxide insufflation. Dig Surg, 2004; 21:95-105.

30. Morgan JR GE, Mikhail MS, Murray MJ- Clinical Anesthesia, $4^{\text {th }}$ Ed, McGraw-Hill: San Francisco, 2006, pp 725-741.

31. Schilling MK, Redaelli $C$, Signer $C$ et al- Splanchnic microcirculatory change during $\mathrm{CO}_{2}$ laparoscopy. J Am Coll Surg, 1997;184: 378-382.

32. Schafer M, Sagesser $\mathrm{H}$, Reichen $\mathrm{J}$ et al- Alterations in hemodynamics and hepatic and splanchnic circulation during laparoscopy in rats. Surg Endosc, 2001; 15: 1197-1201.

33. Koivusalo AM, Kellokumpu I, Ritkari S et al.- Splanchnic and renal deterioration during and after laparoscopic cholecystectomy: a comparison of the carbon dioxide pneumoperitoneum and the abdominal wall lift method. Anesth Analg, 1997;85: 886-891.

34. Ishizaki $\mathrm{Y}$, Bandai $\mathrm{Y}$, Shimomura $\mathrm{K}$ et al.- Changes in splanchnic blood flow and cardiovascular effects following peritoneal insufflation of carbon dioxide. Surg Endosc, 2004;7: 420-423.

35. Bendet N, Morozov V, Lavi R et al.- Does laparoscopic cholecystectomy influence peri-sinusoidal cell activity?. Hepatogastroenterology, 1999;46:1603-1606.

36. Shimogai M, Iranami H, Yamazaki A et al. - Transient but profound reduction of bispectral index values after tourniquet deflation: did the BIS detect an alteration of brain electrocortical activity?. Anesth Analg, 2006; 103: 1613-1614.

37. Dewar D, Underhill SM, Goldberg MP- Oligodendrocytes and ischemic brain Injury. Journal of Cerebral Blood Flow \& Metabolism, 2003; 23: 263-274.

38. Juurlink BH, Thorburne SK, Hertz L - Peroxide-scavenging deficit underlies oligodendrocyte susceptibility to oxidative stress. Glia, 1998; 22: 371-378.

39. Thorburne SK, Juurlink BH- Low glutathione and high iron govern the susceptibility of oligodendroglial precursors to oxidative stress. $\mathrm{J}$ Neurochem, 1996; 67: 1014-1022.

40. Seagard JL, Hopp FA, Bosnjak ZJ et al.- Sympathetic efferent nerve activity in conscious and isoflurane-anesthetized dogs. Anesthesiology, 1984; 61: 266-270.

41. Seagard JL, Hopp FA, Donegan JH et al.- Halotane and the carotid sinus reflex: evidence for multiple sites of action. Anesthesiology, 1982; 57:191-202.

42. Muzi M, Ebert TJ- A randomized, prospective comparison of halothane, isoflurane and enflurane on baroreflex control of heart rate in humans. Adv Pharmacol, 1994; 31: 379-87. 
43. Kotrly KJ, Ebert TJ, Vucins EJ et al. - Human baroreceptor control of heart rate under isoflurane anesthesia. Anesthesiology, 1984;60:173-179.

44. Tanaka M, Nishikawa T- Arterial baroreflex function in humans anaesthetized with sevoflurane. Br J Anaesth, 1999; 82: 350-354.

45. Ebert T, Muzi M, Lopatka C- Neurocirculatory responses to sevoflurane in humans: a comparison to desflurane. Anesthesiology, 1995; 83: 88-95.

46. Ebert TJ, Kotrly KJ, Madsen KS et al.- Fentanyl-diazepam anesthesia with or without $\mathrm{N}_{2} \mathrm{O}$ does not attenuate cardiopulmonary baroreflexmediated vasoconstrictor responses to controlled hypovolemia in humans. Anesth Analg, 1988;67:548-554.

47. Kotrly KJ, Ebert TJ, Vucins EJ et al.- Effects of fentanyl-diazepamnitrous oxide anaesthesia on arterial baroreflex control of heart rate in man. Br J Anaesth, 1986; 58:406-414.

48. Olshan AR, O'connor DT, Cohen IM et al.- Baroreflex dysfunction in patients with adult-onset diabetes and hypertension. Am J Med, 1983; 74: 233-242.

49. Gribbin B, Pickering TG, Sleight $P$ et al.- Effect of age and high blood pressure on baroreflex sensitivity in man. Circulation Research, 1971;29: 424-431. 